\title{
Effect of butyrate on the heregulin/ErbB-mediated proliferation of human colorectal cancer cells
}

\author{
SOO-JEONG LIM ${ }^{1 *}$, MOON-KYUNG CHOI ${ }^{2 *}$ MIN JUNG KIM ${ }^{1}$ and CHANG-HUN LEE ${ }^{2}$ \\ ${ }^{1}$ Department of Bioscience and Biotechnology, Sejong University, Seoul; \\ ${ }^{2}$ Research Institute, National Cancer Center, Goyang, Gyeonggi, Korea
}

Received October 13, 2008; Accepted March 3, 2009

DOI: 10.3892/mmr_00000127

\begin{abstract}
The expression of ErbB proteins, together with heregulin, was found to be increased in colon cancer cells compared with normal mucosa, and heregulin-stimulated activation of ErbB signaling was observed to contribute to the proliferation of colon cancer cells. Butyrate produced during the fermentation of fiber by intestinal bacteria is known to exert diverse anticancer effects, including the induction of differentiation, cell cycle arrest and growth suppression in human colon cancer cells. In this study, we investigated whether butyrate affects the heregulin/ErbB-mediated proliferation of colon cancer cells. The growth of human CaCo-2 and SNU-C4 colon cancer cells, which express ErbB1-4 proteins, was stimulated by heregulin in a concentrationdependent manner. Pretreatment with sodium butyrate abolished heregulin-stimulated proliferation in both cell lines. Although butyrate did not alter ErbB protein expression and activation, it did block the prolonged activation of Akt and Erk1/2, which are known to be important ErbB downstream molecules mediating heregulin-stimulated proliferation. Our data suggest that the inhibitory effects of butyrate on the heregulin-stimulated proliferation of colorectal cancer cells are, in part, associated with the suppression of the Akt and Erk signaling pathway. Butyrate may act as a preventive and therapeutic agent in the progression of colorectal cancer through the regulation of heregulin-stimulated mitogenic signaling.
\end{abstract}

\section{Introduction}

The ErbB family of receptor tyrosine kinases (RTKs) includes epidermal growth factor receptor (EGFR) and ErbB1, 2, 3 and

Correspondence to: Dr Soo-Jeong Lim, Department of Bioscience and Biotechnology, Sejong University, 98 Kunja-dong, Kwangjin-gu, Seoul 143-747, Korea

E-mail: sjlim@sejong.ac.kr

${ }^{*}$ Contributed equally

Key words: heregulin, butyrate, Akt, Erk, proliferation, colon cancer
4. Expression of ErbB proteins, particularly ErbB2 and ErbB3, was found to be increased in colon cancer cells compared with normal mucosa (1). In addition, the co-expression with ErbB proteins of heregulin, a ligand for the ErbB3 and ErbB4 RTKs, was found in human colon cancer specimens obtained from patients and in established colon cancer cell lines $(2,3)$. Heregulin induces the formation of heterodimers between ErbB3 and ErbB2 or between ErbB4 and ErbB2, thereby transactivating ErbB2 $(4,5)$ with other members of the ErbB family. This results in pro-growth and pro-survival signaling through the phosphoinositide-3-kinase (PI3K)/Akt and/or Ras/Raf/Erk pathways (6). Thus, heregulin-stimulated activation of ErbB signaling contributes to the proliferation of colon cancer cells (7), and also plays a role in conferring resistance to anticancer agents (8). In this regard, an agent that can block heregulin-stimulated ErbB signaling may be effective in the prevention and treatment of colon cancer.

Short-chain fatty acids such as acetate, butyrate and propionate are produced during the fermentation of fiber by endogenous intestinal bacteria. Several studies suggest that the production of short-chain fatty acids such as butyric acid in the normal colonic mucosa may play a role in preventing colon carcinogenesis (9). Furthermore, multiple lines of existing evidence suggest that the sodium salt of the fatty acid sodium butyrate is effective in inducing differentiation, cell cycle arrest and growth inhibition in colon cancer cells, acting as a potent anticancer agent (10).

In molecular terms, butyrate is an inhibitor of histone deacetylase (HDAC), which plays an important role in the transcriptional regulation of gene expression (11). Recently, treatment with HDAC inhibitors was shown to induce the acetylation of heat shock protein 90, which inhibited ATP binding and chaperone association with its client proteins, including ErbB2 (12). HDAC inhibitors, such as trichostatin A and SAHA, downregulated ErbB2 protein expression in breast and lung cancer cells $(13,14)$. Butyrate was also identified as a potent and relatively specific ErbB2 promoter-inhibiting agent (15). Based on these reports, we hypothesized that butyrate may inhibit the heregulin-stimulated signaling of colon cancer cells by downregulating ErbB protein expression. Here, we show that butyrate inhibits heregulin/ErbB-stimulated proliferation in human colon cancer cells. Our data suggest that butyrate blocks the prolonged activation of the ErbB downstream molecules that mediate heregulin-stimulated proliferation, without affecting the expression of ErbB proteins. 


\section{Materials and methods}

Cell lines and reagents. Human CaCo-2 colon cancer cell lines were obtained from the American Type Culture Collection (Manassas, VA, USA), while human SNU-C4 colon cancer cell lines were obtained from the Korean Cell Line Bank (Seoul, Korea). Cells were cultured in RPMI-1640 medium supplemented with $100 \mathrm{U} / \mathrm{ml}$ penicillin/streptomycin and $10 \%$ heat-inactivated fetal bovine serum (FBS, Hyclone, Logan, UT) and grown in incubators in a humid atmosphere of $95 \%$ air $/ 5 \% \mathrm{CO}_{2}$.

Hereglin- 1 , sodium butyrate, 3-(4,5-dimethylthiazol-2yl)-2,5-diphenyltetrazolium bromide (MTT) and antibodies to human $\beta$-actin were purchased from Sigma (St. Louis, MO, USA). Phosphospecific and non-phosphospecific antibodies to Erk and Akt were obtained from Cell Signaling Technology (Beverly, MA, USA). Antibodies to ErbB1 were purchased from Santa Cruz Biotechnology (Santa Cruz, CA, USA). Antibodies to ErbB2-4 were purchased from Calbiochem (San Diego, CA, USA). Antibodies against phosphotyrosine (PY20) were obtained from BD Pharmingen (San Diego, CA, USA). All other chemicals were of reagent grade and were used without further purification.

Cell growth and viability assay. Cells were seeded in 96-well plates in $0.1 \mathrm{ml}$ of RPMI media supplemented with 10\% FBS. On the following day, cells were treated with the appropriate reagents. When required, the culture medium was changed to RPMI supplemented with $2 \%$ charcoal-stripped serum (CSS) before the addition of the reagents. Cell growth and viability were measured using MTT. The formation of formazan crystals by active mitochondrial respiration in cells was determined using a microplate spectrophotometer (BioTek, Winooski, VT) after dissolving the crystals in DMSO.

Immunoblotting. Cells were removed from the plates by scraping, washed twice with phosphate-buffered saline (PBS), and suspended in lysis buffer [150 mM NaCl, $10 \mathrm{mM}$ Tris, $0.2 \%$ Triton X-100, 0.3\% NP-40, $0.2 \mathrm{mM} \mathrm{Na}_{3} \mathrm{VO}_{4}$ and protease inhibitor mixture (Roche Diagnostics), $\mathrm{pH}$ 7.4] on ice for 15-30 min. Aliquots of cell lysates containing equal amounts of protein were denatured in SDS-reducing buffer by boiling for $5 \mathrm{~min}$, resolved on SDS-polyacrylamide gels, and transferred to nitrocellulose membranes. The resulting blots were blocked with $5 \%$ nonfat dry milk and incubated with specific primary antibodies, then further incubated with appropriate peroxidase-conjugated secondary antibodies and developed with ECL Plus reagent (Amersham, Arlington Heights, IL) according to the manufacturer's protocol.

Immunoprecipitation. Cell lysates were prepared as described above and pre-cleared with Protein A-conjugated agarose beads (Gibco/BRL). ErbB2 proteins were immunoprecipitated with $1 \mu \mathrm{g}$ of anti-ErbB2 antibody and $10 \mu \mathrm{l}$ of Protein A-agarose for $16 \mathrm{~h}$ at $4^{\circ} \mathrm{C}$. Beads were washed twice with lysis buffer and subjected to $4-12 \%$ Tris-glycine polyacrylamide gel electrophoresis. The separated proteins were transferred to nitrocellulose membranes and blocked in 5\% skim milk in PBST (PBS supplemented with $0.2 \%$ Tween-20). The membranes were then probed with anti-phosphotyrosine and anti-ErbB2.

\section{Results}

Mitogenic effect of heregulin in ErbB-expressing colon cancer cells. When we measured the expression of ErbB1-4 proteins in $\mathrm{CaCo}-2$ and SNU-C4 cells, we found that all ErbB1-4 proteins were expressed in both cell lines, although ErbB4 was minimally detectable in CaCo-2 cells (Fig. 1A). Consistent with our data, high expression of ErbB1 and/or ErbB2 in both cell lines was reported in previous studies (16-18). As expected based on the ErbB protein expression data, the proliferation of both cells was stimulated by heregulin in a concentration-dependent manner. The proliferation of CaCo-2 and SNU-C4 cells was increased in up to 138 and $146 \%$ of the control cells after a 48-h incubation with increasing concentrations of heregulin (Fig. 1B). Although ErbB1 was highly expressed in both cell lines, the addition of EGF, an ErbB1 ligand, was only minimally effective in inducing proliferation (data not shown), suggesting that heregulin is a more potent mitogen than EGF in these cell lines.

\section{Effect of butyrate on heregulin/ErbB-mediated proliferation.}

To examine the effect of butyrate on heregulin-stimulated proliferation, cells were pretreated with sodium butyrate for $30 \mathrm{~min}$ before stimulation with heregulin. Butyrate inhibited the heregulin-stimulated proliferation of SNU-C4 cells, while neither acetate nor propionate was efficient in blocking heregulin-stimulated proliferation (Fig. 2A). Furthermore, inhibition by butyrate was dose-dependent: pretreatment with 3-4 mM butyrate almost completely abolished heregulinstimulated proliferation in both SNU-C4 and CaCo-2 cells (Fig. 2B). These data suggest that the butyrate type of shortchain fatty acids specifically inhibits the heregulin-stimulated proliferation of colon cancer cells.

Effect of butyrate on ErbB expression/activation. We next examined the changes in ErbB protein expression following butyrate treatment in order to elucidate the underlying mechanism by which butyrate inhibits heregulin-stimulated proliferation. Immunoblot analysis revealed that there was no change in the expression of any of the ErbB proteins after treatment with a concentration of butyrate of up to of $4 \mathrm{mM}$ (Fig. 3A; data not shown for $\mathrm{CaCo}-2$ cells).

Heregulin binds with high affinity to ErbB3 and ErbB4, thus inducing the formation of heterodimers. Since ErbB2 is the preferred partner of all ErbB family members (19), inhibiting the function of ErbB2 might lead to the blockade of the cellular transformation and proliferation processes induced by heregulin $(20,21)$. To investigate the possibility that butyrate blocked ErbB2 activation without affecting its expression, we performed immunoprecipitation analysis with the cell lysates obtained after heregulin stimulation with or without butyrate pretreatment. A 5-min incubation with heregulin markedly increased the level of phosphorylated ErbB2. However, butyrate pretreatment did not affect the phosphorylation of ErbB2, regardless of the pretreatment period (Fig. 3B). These data suggest that the inhibitory effect of butyrate on heregulininduced proliferation cannot be mainly attributed to the direct inhibition of ErbB proteins.

Effect of butyrate on Erk and Akt activation. Previous studies have shown that the mitogenic effect of heregulin in ErbB- 
A

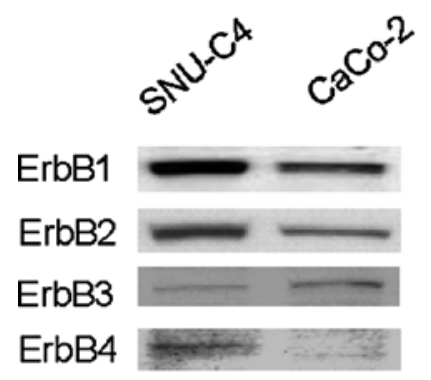

B

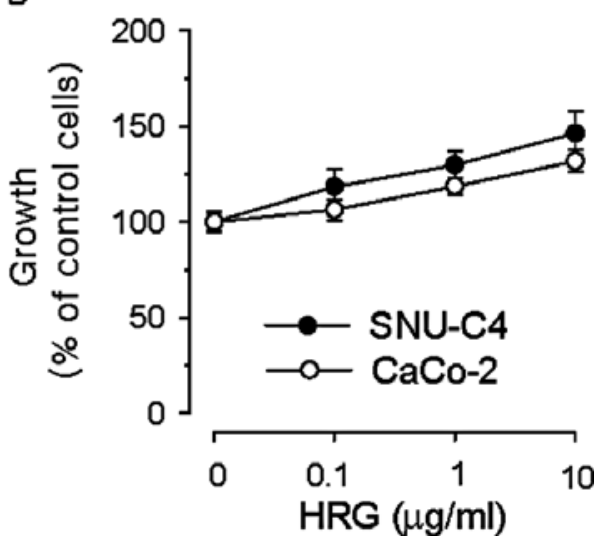

Figure 1. Heregulin increased the proliferation of human SNU-C4 and CaCo-2 colon cancer cells in a dose-dependent manner. (A) Expression of ErbB1, 2, 3 and 4 proteins in SNU-C4 and CaCo-2 cells. Cell lysates were obtained from exponentially growing cells and subjected to immunoblotting with the appropriate antibodies. (B) The proliferation of human SNU-C4 and CaCo-2 colon cancer cells by heregulin was dose-dependent. Cells were seeded at a density of $3 \times 10^{3} /$ well in 96-well plates. After $24 \mathrm{~h}$, culture media were changed with media supplemented with $2 \%$ CSS. At $48 \mathrm{~h}$ post-incubation with varying concentrations of heregulin (HRG), cell growth and viability were determined by the MTT assay. Results are expressed as the percentage of growth (mean \pm SD of triplicate wells) relative to untreated cells.

A

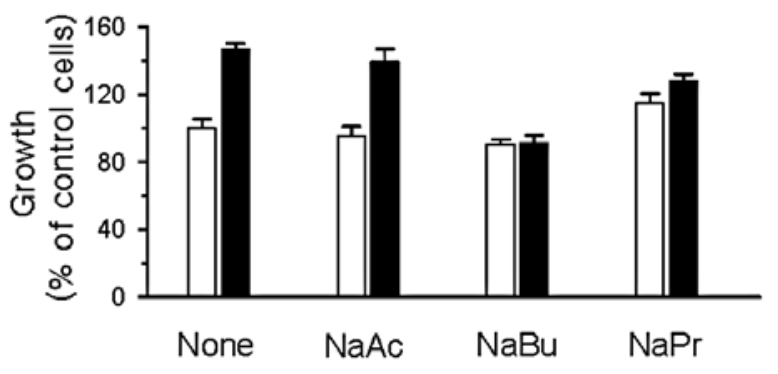

B
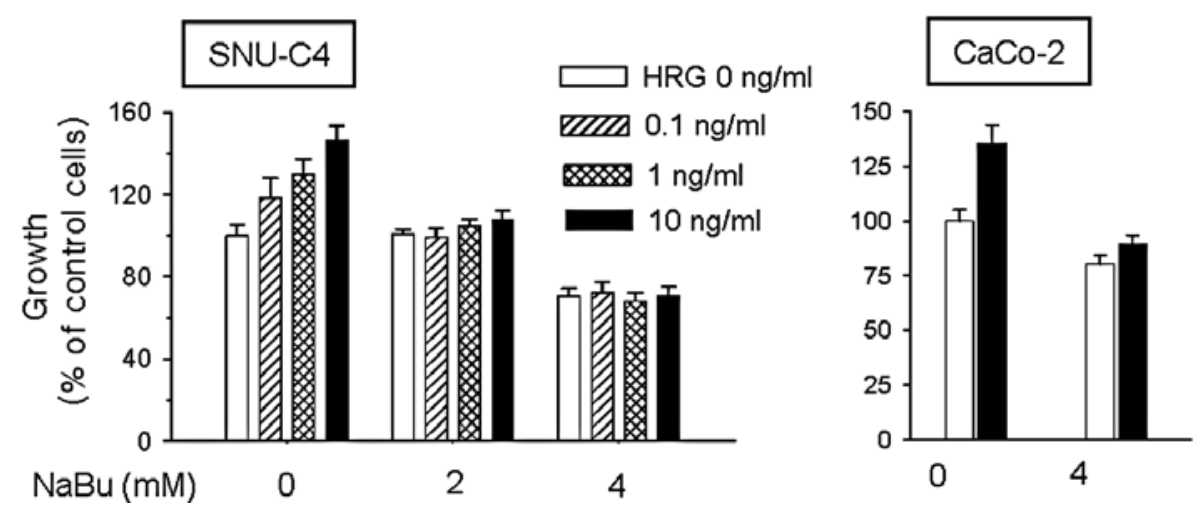

Figure 2. Sodium butyrate inhibited the heregulin-induced proliferation of colon cancer cells. (A) Effect of the addition of acetate, butyrate or propionate on the heregulin-stimulated growth of SNU-C4 cells. Cells pretreated with $3 \mathrm{mM}$ of each short chain fatty acid for $2 \mathrm{~h}$ were incubated with $10 \mathrm{ng} / \mathrm{ml}$ heregulin in the presence of $2 \%$ CSS. At $72 \mathrm{~h}$ post-incubation, cell growth and viability were determined by the MTT assay. Results are expressed as the percentage of growth (mean \pm SD of triplicate wells) relative to untreated cells. (B) Inhibition by butyrate of the heregulin-stimulated growth of SNU-C4 and CaCo-2 cells. Cells pretreated with 0,2 or $4 \mathrm{mM}$ butyrate for $2 \mathrm{~h}$ were incubated with increasing concentrations of heregulin in the presence of $2 \%$ CSS. At $72 \mathrm{~h}$ post-incubation, cell growth and viability were determined by the MTT assay. Results are expressed as the percentage of growth (mean \pm SD of triplicate wells) relative to untreated cells.

expressing cancer cells is associated with the integration of multiple signaling pathways, including those involving prolonged activation of Erk and PI3K/Akt, which results from dimer formation between the ErbB proteins $(6,22,23)$. To investigate the possibility that butyrate inhibits the downstream signaling pathways after ErbB activation, we performed immunoblot analysis to analyze changes in the phosphorylation of the Akt and Erk proteins. In both SNU-C4 and CaCo-2 cells, the phosphorylation of Erk $1 / 2$ and Akt was rapidly induced as early as $15 \mathrm{~min}$ after heregulin addition, and was 

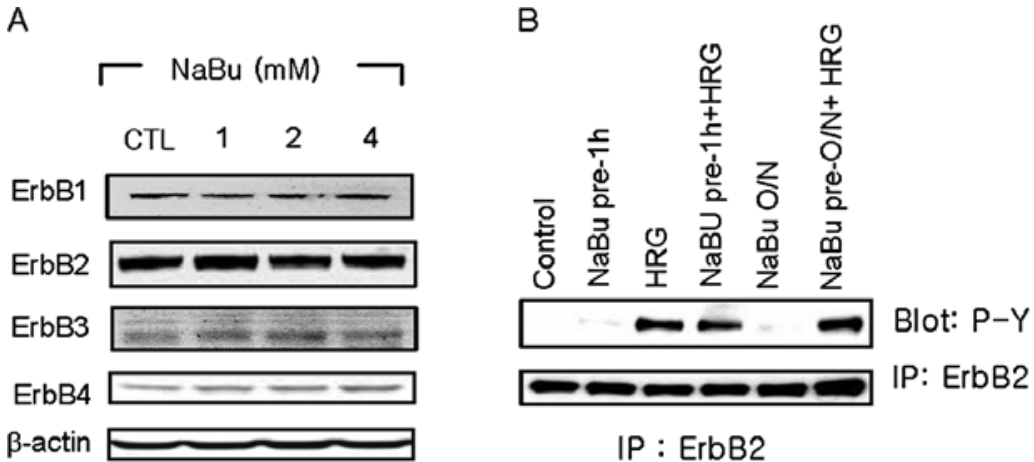

Figure 3. Butyrate did not change the expression and activation of ErbB proteins. (A) Effect of butyrate on the expression of ErbB1-4 proteins. SNU-C4 cells were treated with increasing doses of butyrate in the presence of $2 \%$ CSS. At $48 \mathrm{~h}$ post-incubation, cell lysates were obtained and subjected to immunoblotting with appropriate antibodies. Immunoblotting with an antibody to $\beta$-actin was used to ensure the equal loading of proteins in each lane. (B) Effect of butyrate on the heregulin-stimulated phosphorylation of ErbB2 proteins. SNU-C4 cells were treated with 4 mM butyrate for 1 or $16 \mathrm{~h}$, followed by stimulation with heregulin for $5 \mathrm{~min}$. Proteins obtained from cell lysates were immunoprecipitated with the anti-ErbB2 antibody, separated by SDS-PAGE, and blotted with anti-phosphotyrosine. Data shown are representative of at least two independent experiments.

A

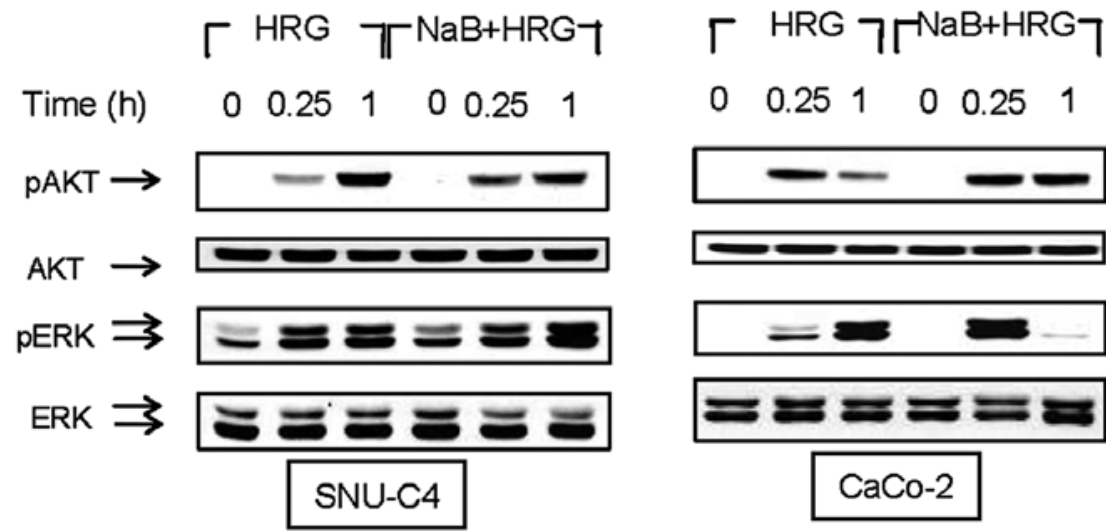

B

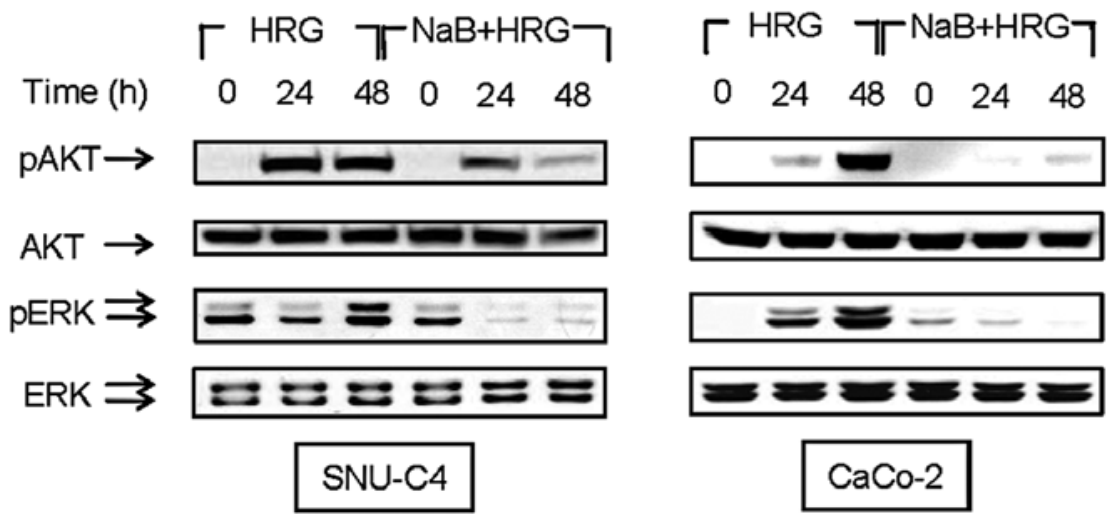

Figure 4. Butyrate inhibited late, but not early, activation of Erk1/2 and Akt proteins in heregulin-stimulated colon cancer cells. After $1 \mathrm{~h}$ of pretreatment with $3 \mathrm{mM}$ butyrate in SNU-C4 and CaCo-2 cells, $10 \mathrm{ng} / \mathrm{ml}$ of heregulin was added to stimulate the cells. Cells were lysed after incubation with heregulin for (A) 0.25 or $1 \mathrm{~h}$ and (B) 24 or $48 \mathrm{~h}$, and proteins were subjected to immuoblot analysis with appropriate antibodies. Data shown are representative of at least four independent experiments.

maintained or increased for up to $1 \mathrm{~h}$. Pretreatment with butyrate did not affect the rapid phosphorylation of Erk1/2 and Akt in SNU-C4 cells (Fig. 4A). In Caco-2 cells, the phosphorylation of Erk proteins rapidly increased and then decreased, while that of Akt was not significantly changed by butyrate pretreatment. Therefore, butyrate pretreatment did not inhibit the activation of Akt and Erk in either cell line.
A more intense mitogenic effect of heregulin as compared with EGF is associated with the prolonged activation of PI3K/Akt and Erk by heregulin (6). When we examined the phosphorylation of these proteins up to $48 \mathrm{~h}$ after heregulin treatment, the increased phosphorylation of Akt was maintained up to $48 \mathrm{~h}$ after heregulin addition, while the phosphorylation of the Erk1/2 proteins was increased after $1 \mathrm{~h}$ of 


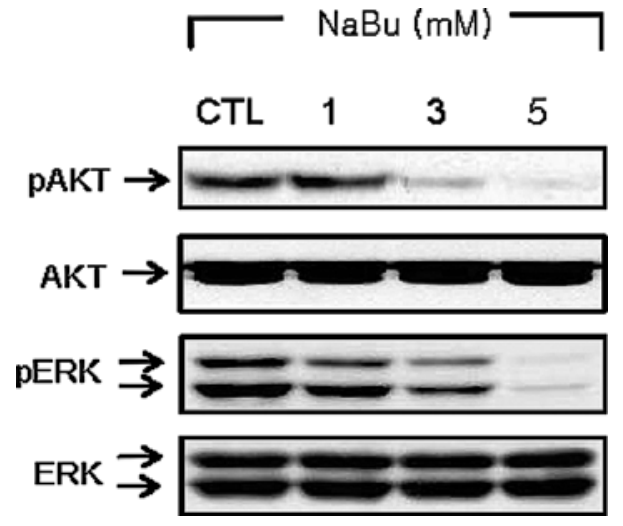

Figure 5. Butyrate inhibited the late activation of Erk1/2 and Akt proteins in a dose-dependent manner. After $1 \mathrm{~h}$ of pretreatment with $3 \mathrm{mM}$ butyrate in SNU-C4 cells, $10 \mathrm{ng} / \mathrm{ml}$ of heregulin was added to stimulate the cells. At $36 \mathrm{~h}$ post-incubation, cells were lysed and proteins were subjected to immunoblot analysis with the appropriate antibodies. Data shown are representative of at least two independent experiments.

incubation, decreased at $24 \mathrm{~h}$, and again increased at $48 \mathrm{~h}$ in both cell lines, suggesting secondary activation (Fig. 4B). Conversely, the phosphorylation of these proteins rapidly decreased $1 \mathrm{~h}$ after the addition of EGF, and no secondary activation was observed (data not shown), in accordance with the relative ineffectiveness of EGF in inducing mitogenic response. To investigate the possibility that butyrate affected the later activation of Akt and/or Erk proteins, we further assayed the phosphorylation of these proteins up to $48 \mathrm{~h}$ after heregulin treatment in the presence or absence of butyrate. In both SNU-C4 and CaCo-2 cells, butyrate pretreatment at doses of $3 \mathrm{mM}$ significantly decreased the phosphorylation of Akt proteins at 24 and $48 \mathrm{~h}$ after the addition of heregulin. The secondary increase in Erk phosphorylation did not occur in either of the cell lines pretreated with butyrate (Fig. 4B). Moreover, the inhibition of heregulin-induced Akt and Erk1/2 activation at $36 \mathrm{~h}$ was dependent on the concentration of butyrate (Fig. 5). This suggests that the butyrate blockade may be associated, at least in part, with the inhibition of later (prolonged) Erk and PI3K/Akt signaling pathways.

\section{Discussion}

In addition to its involvement in a variety of colonic mucosal functions, butyrate is known to inhibit the initiation and progression of colon cancer by acting as a regulator of multiple signals involved in the progression of cancer. In multiple colorectal cancer cell lines, butyrate has shown inhibitory effects on decay-accelerating factor (DAF) induction (24), pro-metastatic metalloproteinase activation (25) and proangiogenetic hypoxia-inducible factor (HIF)-1 $\alpha$ activation (26). Butyrate also has antiproliferative effects by inducing cell cycle arrest and/or apoptosis through interaction with the caspase signaling cascade. Here, we describe another important regulatory function of butyrate, which is to block the heregulin/ ErbB-stimulated mitogenic response in colon cancer cells. The exogenous addition of heregulin $B$ induced the proliferation of ErbB-expressing cancer cells, whereas it failed to do so in the presence of butyrate. The butyrate concentrations used in our study (1-3 mM) are somewhat lower than those found in human feces (11-25 mM) (8), suggesting that the butyrate produced by the bacterial fermentation of dietary fibers in the colon lumen may be capable of blocking the heregulin/ErbBstimulated mitogenic response of cancer cells.

Based on the published data, which indicate that HDAC inhibitors, including butyrate, modulate the expression of ErbB2 proteins through HDAC inhibitory action in breast and lung cancer cells (14), we initially tested the possibility that butyrate could downregulate ErbB expression. However, butyrate at the 1-3 $\mathrm{mM}$ doses used in this study did not change the expression and activation of ErbB proteins in colorectal cancer cells. Since these doses of butyrate can increase the acetylation of $\mathrm{H} 3$ proteins (unpublished data), suggesting that they are enough to exert an HDAC inhibitory effect, it seems unlikely that butyrate inhibited heregulin-stimulated mitogenic signaling through the modulation of ErbB protein expression. It remains to be determined if the HDAC inhibitory action of butyrate contributed to its inhibitory effect on heregulinstimulated mitogenic signaling.

Previous studies have shown that the PI3K/Akt and MAPK/Erk1/2 pathways are major downstream signaling pathways mediating heregulin/ErbB mitogenic signaling (27-29). The intensity and duration of these signaling pathways are important factors determining the intensity of the mitogenic response of cells (6). Therefore, we also tested whether butyrate could suppress these downstream pathways without inhibiting the ErbB proteins. In our system, butyrate did not alter the early phosphorylation of the Akt and Erk proteins (for up to $1 \mathrm{~h}$ ), but significantly blocked the prolonged phosphorylation of these proteins (at 24 and $48 \mathrm{~h}$ ) without affecting their expression. Inhibition of late Akt and Erk1/2 activation by butyrate was dose-dependent. Our data suggest that the butyrate effect on heregulin-induced proliferation may be associated, at least in part, with the inhibition of late PI3k/Akt and Erk activation. It is plausible that blocking both pathways led to the inhibition of the proteins involved in heregulin/ErbB-mediated proliferation, such as cyclin D1 or c-myc (6). The present study did not determine the mechanism responsible for the butyrate regulation of Akt and Erk1/2 activity. Butyrate might directly or indirectly inhibit Akt and Erk1/2 activation.

In addition to colorectal cancer, heregulin is known to be expressed in approximately $30 \%$ of breast cancer malignancies (30). In many studies, heregulin plays a critical role in inducing the tumorigenicity and metastasis of breast cancer cells. Therefore, it would be of concern to examine the effect of butyrate on breast cancer. Although the clinical utility of sodium butyrate is limited by its short half-life in vivo (31), the use of tributyrin, a prodrug that can be cleaved intracellularly by lipases into three molecules of butyrate, exhibits more favorable pharmacokinetics than butyrate, and might allow for the circumvention of the problem of the fast metabolism of butyrate monomers $(32,33)$.

\section{Acknowledgements}

This work was supported by a research grant (No. 0710251) from the National Cancer Center to C.H. Lee. 


\section{References}

1. Maurer CA, Friess H, Kretschmann B, et al: Increased expression of erbB3 in colorectal cancer is associated with concomitant increase in the level of erbB2. Hum Pathol 29: 771-777, 1998.

2. Venkateswarlu S, Dawson DM, St. Clair P, Gupta A, Willson JK and Brattain MG: Autocrine heregulin generates growth factor independence and blocks apoptosis in colon cancer cells. Oncogene 21: 78-86, 2002.

3. Cho HJ, Kim WK, Kim EJ, et al: Conjugated linoleic acid inhibits cell proliferation and ErbB3 signaling in HT-29 human colon cell line. Am J Physiol Gastrointest Liver Physiol 284: G996-G1005, 2003.

4. Plowman GD, Green JM, Culouscou JM, Carlton GW, Rothwell VM and Buckley S: Heregulin induces tyrosine phosphorylation of HER4/p180erbB4. Nature 366: 473-475, 1993.

5. Sliwkowski MX, Schaefer G, Akita RW, et al: Coexpression of erbB2 and erbB3 proteins reconstitutes a high affinity receptor for heregulin. J Biol Chem 269: 14661-14665, 1994.

6. Neve RM, Holbro T and Hynes NE: Distinct roles for phosphoinositide 3-kinase, mitogen-activated protein kinase and p38 MAPK in mediating cell cycle progression of breast cancer cells. Oncogene 21: 4567-4576, 2002.

7. Jackson JG, St. Clair P, Sliwkowski MX and Brattain MG: Blockade of epidermal growth factor- or heregulin-dependent ErbB2 activation with the anti-ErbB2 monoclonal antibody $2 \mathrm{C} 4$ has divergent downstream signaling and growth effects. Cancer Res 64: 2601-2609, 2004.

8. Tari AM, Lim SJ, Hung MC, Esteva FJ and Lopez-Berestein G: Her2/neu induces all-trans retinoic acid (ATRA) resistance in breast cancer cells. Oncogene 21: 5224-5232, 2002.

9. Hague A, Manning AM, Hanlon KA, Huschtscha LI, Hart D and Paraskeva C: Sodium butyrate induces apoptosis in human colonic tumour cell lines in a p53-independent pathway: implications for the possible role of dietary fibre in the prevention of large-bowel cancer. Int J Cancer 55: 498-505, 1993.

10. Augenlicht LH, Mariadason JM, Wilson A, et al: Short chain fatty acids and colon cancer. J Nutr 132: 3804S-3808S, 2002.

11. Sealy L and Chalkley R: The effect of sodium butyrate on histone modification. Cell 14: 115-121, 1978.

12. Yu X, Guo ZS, Marcu MG, et al: Modulation of p53, ErbB1, ErbB2, and Raf-1 expression in lung cancer cells by depsipeptide FR901228. J Natl Cancer Inst 94: 504-513, 2002.

13. Bali P, Pranpat M, Swaby R, et al: Activity of suberoylanilide hydroxamic acid against human breast cancer cells with amplification of her-2. Clin Cancer Res 11: 6382-6389, 2005.

14. Noh EJ, Jang ER, Jeong G, Lee YM, Min CK and Lee JS: Methyl CpG-binding domain protein 3 mediates cancer-selective cytotoxicity by histone deacetylase inhibitors via differential transcriptional reprogramming in lung cancer cells. Cancer Res 65: 11400-11410, 2005.

15. Scott GK, Marden C, Xu F, Kirk L and Benz CC: Transcriptional repression of ErbB2 by histone deacetylase inhibitors detected by a genomically integrated ErbB 2 promoter-reporting cell screen. Mol Cancer Ther 1: 385-392, 2002.

16. Nyati MK, Maheshwari D, Hanasoge S, et al: Radiosensitization by pan ErbB inhibitor CI-1033 in vitro and in vivo. Clin Cancer Res 10: 691-700, 2004.

17. Skvortsov S, Sarg B, Loeffler-Ragg J, et al: Different proteome pattern of epidermal growth factor receptor-positive colorectal cancer cell lines that are responsive and nonresponsive to C225 antibody treatment. Mol Cancer Ther 3: 1551-1558, 2004.
18. Karnes WE Jr, Walsh JH, Wu SV, et al: Autonomous proliferation of colon cancer cells that coexpress transforming growth factor alpha and its receptor. Variable effects of receptor-blocking antibody. Gastroenterology 102: 474-485, 1992.

19. Graus-Porta D, Beerli RR, Daly JM and Hynes NE: ErbB-2, the preferred heterodimerization partner of all ErbB receptors, is a mediator of lateral signaling. EMBO J 16: 1647-1655, 1997.

20. Alimandi M, Romano A, Curia MC, et al: Cooperative signaling of ErbB3 and ErbB2 in neoplastic transformation and human mammary carcinomas. Oncogene 10: 1813-1821, 1995.

21. Lewis GD, Lofgren JA, McMurtrey AE, et al: Growth regulation of human breast and ovarian tumor cells by heregulin: Evidence for the requirement of ErbB2 as a critical component in mediating heregulin responsiveness. Cancer Res 56: 1457-1465, 1996.

22. Fiddes RJ, Campbell DH, Janes PW, et al: Analysis of Grb7 recruitment by heregulin-activated erbB receptors reveals a novel target selectivity for erbB3. J Biol Chem 273: 7717-7724, 1998.

23. Sepp-Lorenzino L, Eberhard I, Ma Z, et al: Signal transduction pathways induced by heregulin in MDA-MB-453 breast cancer cells. Oncogene 12: 1679-1687, 1996.

24. Andoh A, Shimada M, Araki Y, Fujiyama Y and Bamba T: Sodium butyrate enhances complement-mediated cell injury via down-regulation of decay-accelerating factor expression in colonic cancer cells. Cancer Immunol Immunother 50: 663-672, 2002.

25. Zeng $\mathrm{H}$ and Briske-Anderson $\mathrm{M}$ : Prolonged butyrate treatment inhibits the migration and invasion potential of HT1080 tumor cells. J Nutr 135: 291-295, 2005.

26. Zgouras D, Wachtershauser A, Frings D and Stein J: Butyrate impairs intestinal tumor cell-induced angiogenesis by inhibiting HIF-1alpha nuclear translocation. Biochem Biophys Res Commun 300: 832-838, 2003.

27. Carraway KL III, Soltoff SP, Diamonti AJ and Cantley LC: Heregulin stimulates mitogenesis and phosphatidylinositol 3 -kinase in mouse fibroblasts transfected with erbB2/neu and erbB3. J Biol Chem 270: 7111-7116, 1995.

28. Vijapurkar U, Kim MS and Koland JG: Roles of mitogenactivated protein kinase and phosphoinositide 3 '-kinase in ErbB2/ErbB3 coreceptor-mediated heregulin signaling. Exp Cell Res 284: 291-302, 2003.

29. Ram TG and Ethier SP: Phosphatidylinositol 3-kinase recruitment by p185erbB-2 and erbB-3 is potently induced by neu differentiation factor/heregulin during mitogenesis and is constitutively elevated in growth factor-independent breast carcinoma cells with c-erbB-2 gene amplification. Cell Growth Differ 7: 551-561, 1996.

30. Lupu R, Cardillo M, Cho C, et al: The significance of heregulin in breast cancer tumor progression and drug resistance. Breast Cancer Res Treat 38: 57-66, 1996.

31. Miller AA, Kurschel E, Osieka R and Schmidt CG: Clinical pharmacology of sodium butyrate in patients with acute leukemia. Eur J Cancer Clin Oncol 23: 1283-1287, 1987.

32. Kuefer R, Hofer MD, Altug V, et al: Sodium butyrate and tributyrin induce in vivo growth inhibition and apoptosis in human prostate cancer. Br J Cancer 90: 535-541, 2004.

33. Gaschott T, Steinhilber D, Milovic V and Stein J: Tributyrin, a stable and rapidly absorbed prodrug of butyric acid, enhances antiproliferative effects of dihydroxycholecalciferol in human colon cancer cells. J Nutr 131: 1839-1843, 2001. 